\title{
Experimental Verification of the Liquid Petroleum Gas (LPG) Tank Material and Improvement of the Fatigue Life According to Lid Geometry by using FEA Technique
}

\author{
Mehmet Hanifi DOĞRU*, İbrahim GÖV** \\ *Pilotage Department, Gaziantep University, Aeronautics and Aerospace Faculty, Gaziantep, Turkey, \\ E-mail: mhdogru@gantep.edu.tr \\ **Gaziantep University, Aeronautics and Aerospace Faculty, Aircraft and Aerospace Engineering Department, \\ Gaziantep, Turkey, E-mail: igov@gantep.edu.tr \\ crossref http://dx.doi.org/10.5755/j01.mech.25.1.21999
}

\section{Introduction}

LPG is defined as a type of fuel, which consists of propane and butane gases that are obtained from natural gas deposits. LPG has no color and odor. In addition, it can be flammable. It is kept in special tanks in liquid form under pressure. LPG tanks can be defined as the pressure vessel.

Prediction of the burst pressures and permanent volume expansions of the vehicle toroidal LPG fuel tanks concept were investigated by using finite element analysis (FEA) and experiments. The experiment was performed hydrostatically in which the cylinders were internally pressurized with water. Analytical and numerical studies using different materials were performed to investigate volume expansion, which it emerged on the LPG tank due to burst pressure [1].

A pressure vessel was designed to calculate the optimum nozzle, head, thickness of the shell, and leg support. Static analysis was caried out to check the stregth of the vessel. Vessel thickness was optimized by using static analysis results. After the optimization, fatigue analysis was carried out on the entire structure of the pressure vessel to caluclte the fatigue life cycle [2]. Numerical investigations of the FEA applied to the strength calculation of a pressure vessel [3]. Load investigation are also investigated by FEA and experimentally to determine the feasible preform forge geometry to reduce the forging load requirement [4].

Winding angle effects on composite overwrapped pressure vessel was investigated by means of FAE. Overwrapping operation of aluminum pressure vessel with Carbon/Epoxy fiber reinforced polymer was simulated. Composite vessel was examined under pure internal pressure and maximum shell displacement, optimum winding angle and pressure required to burst were obtained [5].

Residual stresses of welded region of LPG storage tanks was reduced by using post weld heat treatment. Weld joints microstructures of single welding process (Shielded Metal-Arc Welding) and combined welding process Shielded Metal-Arc Welding and Submerged-Arc Welding) were examined. In addition, heat-affected zone of welding's was investigated in terms of hardness [6].

FEA is used to obtain mechanical properties of carbon fibre reinforced Plastic composite pressure vessel. Pressure loads were used to calculate stress values of composite pressure vessel. Different internal pressures, test hydraulic pressures, minimum destructive pressure and working pressure were considered as pressure load [7].
The risk impact of LPG storage facilities was investigated during the LPG tank explosion. Planas-Cuchi method was chosen to obtain maximum side-on overpressure of the LPG tank during explosion [8].

Different sheet metal thicknesses were considered for LPG tanks manufactured from carbon steel and the busting resistance of these tanks were investigated numerically and experimentally. Minimum sheet thickness for LPG tank production in industry was found as a result of bursting pressure test [9].

Different alternative materials were used to minimize weight of LPG cylinder. LPG cylinders was subjected to FEA and Steel, Aluminium $6061 \mathrm{T6}$ and Aluminium 5052-H38 alloy were assigned as cylinder material. Weight of the cylinders were calculated, and the lightest material was chosen for the new LPG cylinder [10].

LPG tank explosions were analyzed experimentally. Hazard factors and process dynamics were determined during test by using data acquisition equipment [11].

The experimental study of explosive combustion of LPG-air mixtures at ambient initial temperature was performed in two closed vessels with central ignition, at various total initial pressures and various fuel/air ratios, within the flammability limits [12].

At the end of the literature survey, it is seen that there is less study about the the lid geometry of the LPG tanks. So, the improvement of the lid radius concept is investigated in this study.

\section{Materials and methods}

\subsection{Numerical study}

Geometric information's of the analysed and tested tank is provided from the public used tanks. Tank geometry is created on the Solid-works modelling part then exported to the ANSYS static structural tool as shown in Fig. 1.

Boundary condition, which are fixed support as shown in Fig. 2, is applied to lower surface of the tank housing part according to the actual assembling conditions.

In normal conditions, the operating pressure of the LPG tank is nearly 9-10 bar. But in the design stage, Factor of safety is taken as 3 on the pressured tanks [13]. And, 30 bar (3 $\mathrm{MPa}$ ) pressure is applied to the tank to perform the analysis as inner pressure as shown in Fig 3.

Zero based loading type was used for the simulations. Soderberg theory was selected. Because the Soderbergh theory is the most conservative. Fatigue modification 
factor was accepted as 1 . The value does not change the results due to performing only comparison of the geometry.

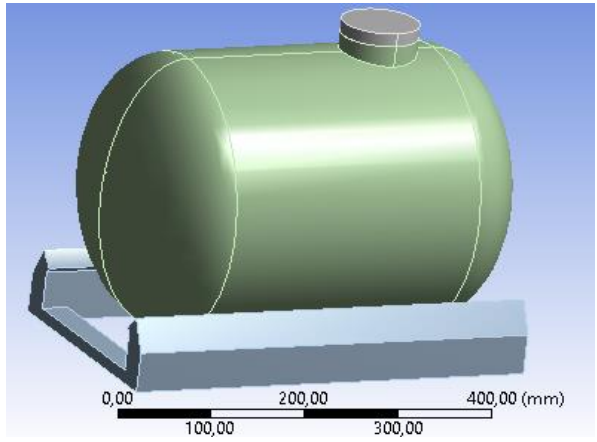

Fig. 1 Geometry of the solid model of the tank

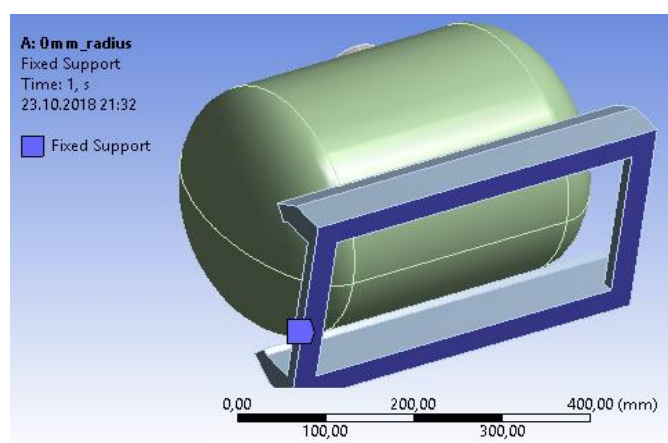

Fig. 2 Support view of the tank

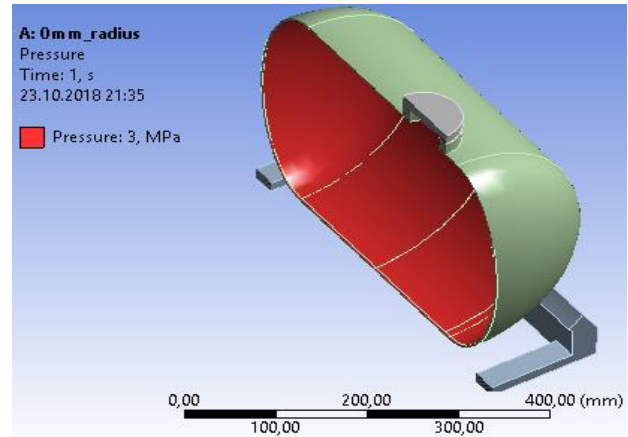

Fig. 3 Loading condition of the tank

\subsubsection{Mesh accuracy}

Mesh accuracy is one of important parameters to achieve accurate analysis result. So, different element number is investigated in terms of the maximum von-Mises stress value as shown in Fig. 4. Free mesh method is applied to the system.

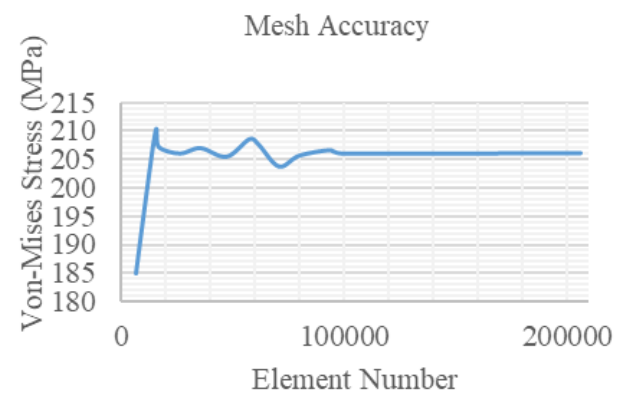

Fig. 4 Mesh accuracy

It is seen that there is no significant change in the von-Mises stress value after the 100000 elements number.
Hence, 100000 element number is used to carry out the analyses. Mesh view is shown as Fig. 5.

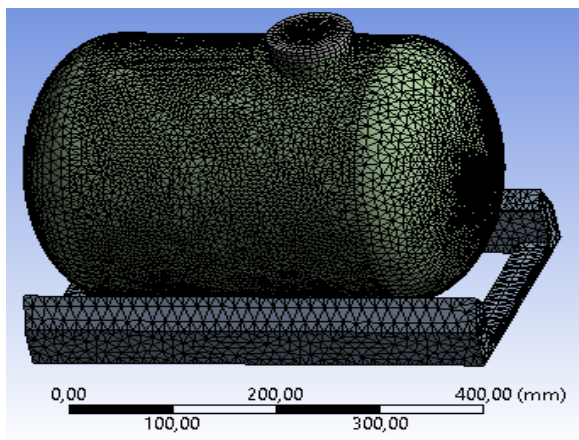

Fig. 5 Mesh view of full body tank

\subsubsection{Static structural analysis of LPG tanks}

Analyses are carried out by using ANSYS static structural analysis tool. $3 \mathrm{MPa}$ (including 3 factor of safety) operating pressure is applied to the tank to determine some parameters.

Von-Mises stress value is obtained as maximum $255 \mathrm{MPa}$ near the lid for the original geometry as shown in Fig. 6.

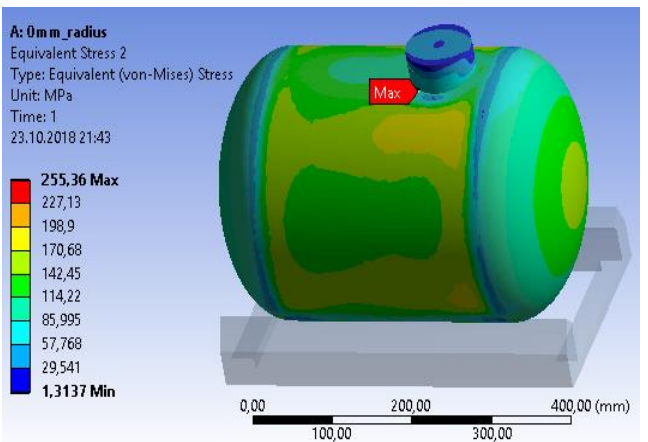

Fig. 6 Von-Mises stress value of original geometry

Lateral stress value is obtained as maximum 267 MPa near the lid for the original geometry as shown in Fig. 7 and total deformation is founded as $\max 0,33 \mathrm{~mm}$ at the side of the tank as shown in Fig. 8.

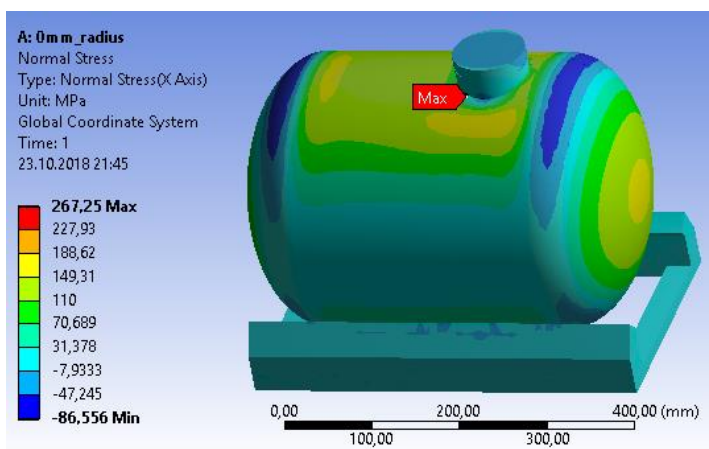

Fig. 7 Lateral stress value of original geometry

At the end of the analysis, safety factor is obtained as 1.03, which is critical value, as shown in Fig. 9 and fatigue life is attained nearly 11000 cycles as shown in Fig. 10.

Fatigue life of pressure vessel was simulated and calculated by using S-N data in ANSYS fatigue tool. Stress life was selected as the fatigue analysis type. 


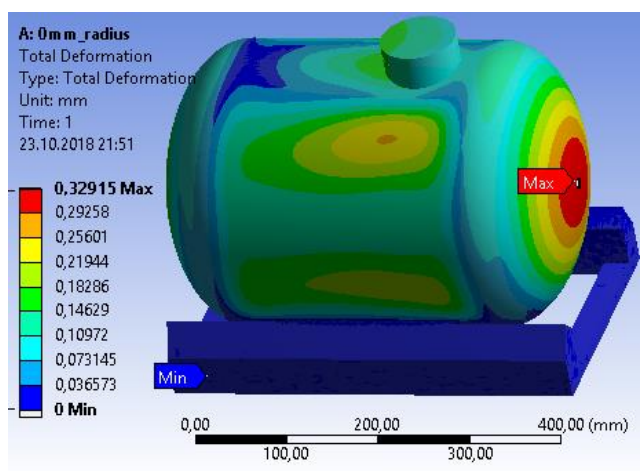

Fig. 8 Total deformation value of original geometry

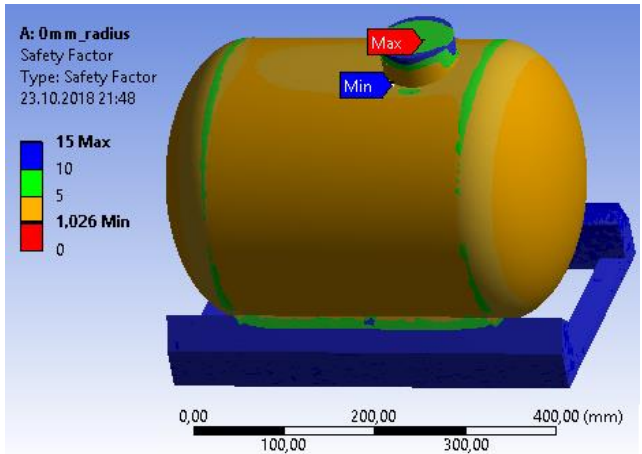

Fig. 9 Safety factor of original geometry

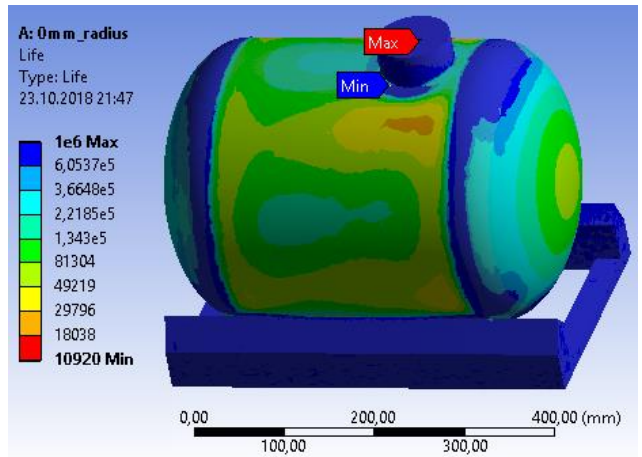

Fig. 10 Fatigue life of original geometry

\subsubsection{Radius investigation of lid}

Radius investigation of lid is performed in this part. Same boundary conditions and loading types are applied to the tank to execute the study. 6 different lid radii are analysed to determine optimum fillet weld size as shown in Fig. 11.

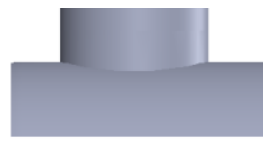

a

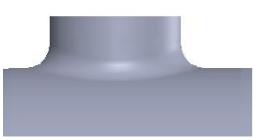

$\mathrm{c}$

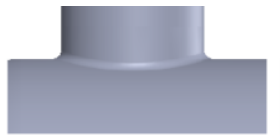

$\mathrm{b}$

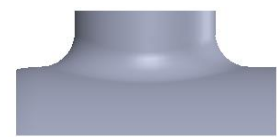

d

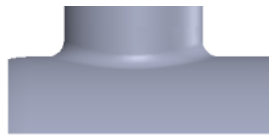

$\mathrm{c}$

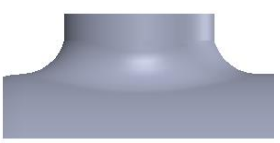

e
Fig. 11 View of the examined different radius size $(a=0 \mathrm{~mm} ; \quad b=5 \mathrm{~mm} ; \quad c=10 \mathrm{~mm} ; \quad d=15 \mathrm{~mm}$; $e=20 \mathrm{~mm} ; f=25 \mathrm{~mm}$ )
Equivalent stress value is obtained as maximum $232 \mathrm{MPa}$ side of the lid for the improved geometry as shown in Fig. 12.

Lateral stress value is obtained as maximum $230 \mathrm{MPa}$ near the lid for the original geometry as shown in Fig. 13 and total deformation is founded as $\max 0,33 \mathrm{~mm}$ at the side of the tank as shown in Fig. 14.

At the end of the analysis, safety factor is obtained as 1.128, which is improved value, as shown in Fig. 15 and fatigue life is attained nearly 15000 cycles as shown in Fig. 16.

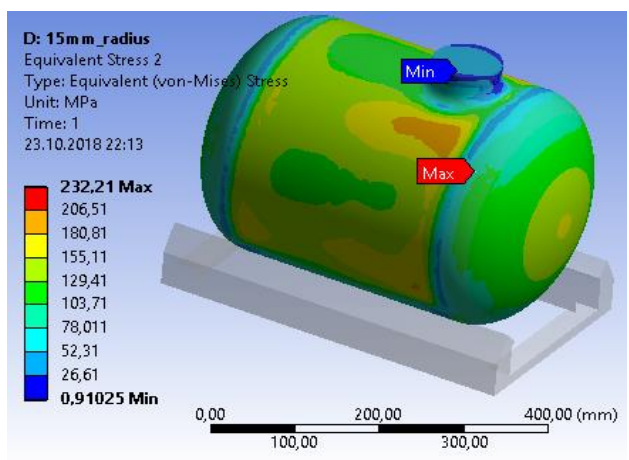

Fig. 12 Equivalent stress value of improvement tank

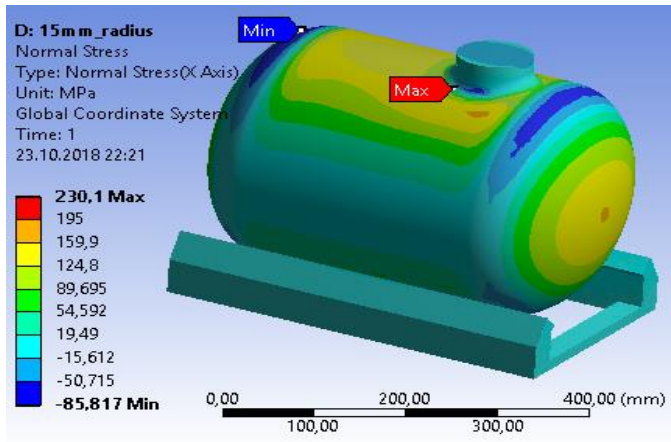

Fig. 13 Lateral stress value of improved tank

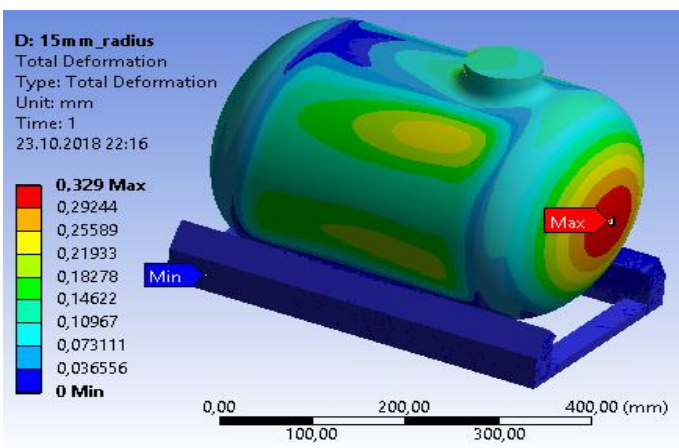

Fig. 14 Total deformation of improved tank

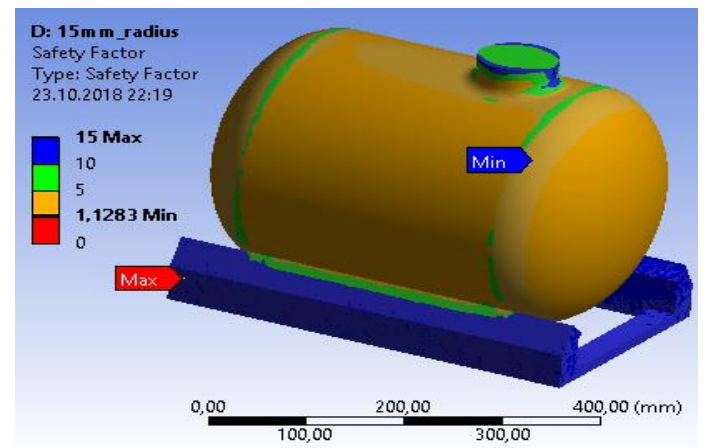

Fig. 15 Safety factor of improved tank 


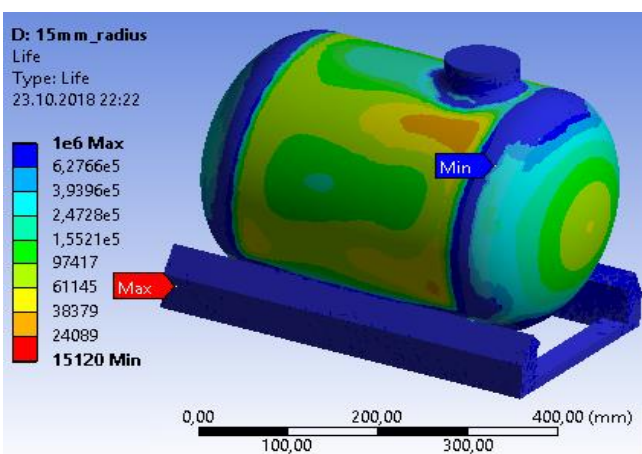

Fig. 16 Fatigue life of improved tank

\subsection{Experimental study}

LPG storage tanks, which are used nearly 10 years (Fig. 17) and new tank (Fig. 18), is used to carry out the experimental study.

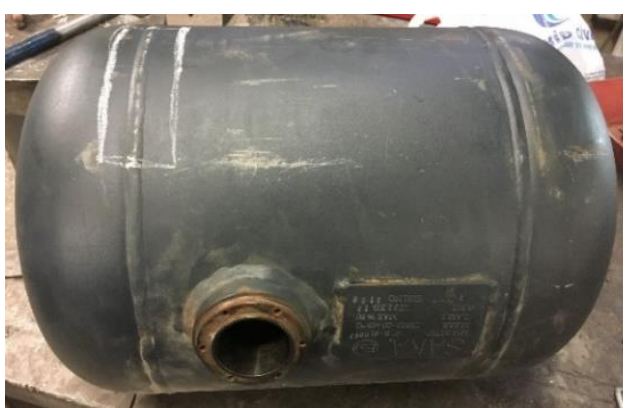

Fig. 17 Ten years LPG tank

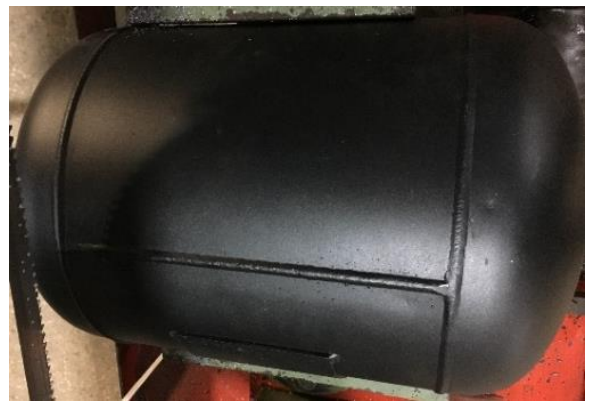

Fig. 18 New LPG tank

The experimental specimens are taken from the same part of the tanks. Material analysis tests are carried out to determine material properties.

Oxford X-MET5100 Hand-held XRF analyzer is used for the material analysis tests is shown is Fig. 19. It is detected that both ten years used and new tank are produced from the same material which is low carbon steel material.

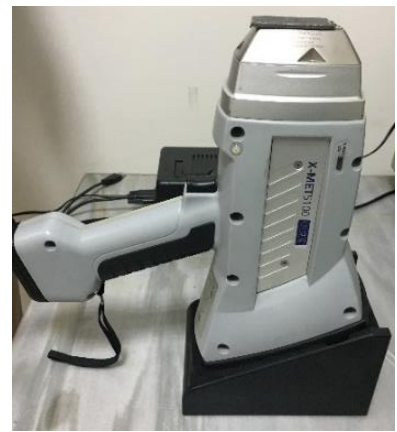

Fig. 19 Oxford X-MET5100 Hand-held XRF analyzer
Test specimen is obtained by using boron liquid cooled automatic cutting machine as shown in Fig. 20 for new tank and in Fig. 21 ten years' tank.

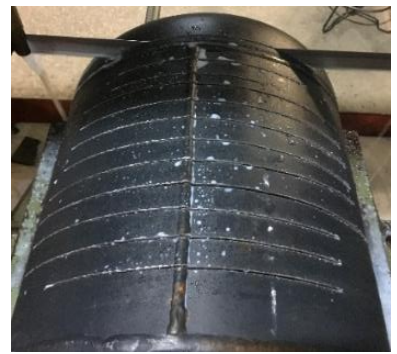

Fig. 20 Cutting operation of new tank

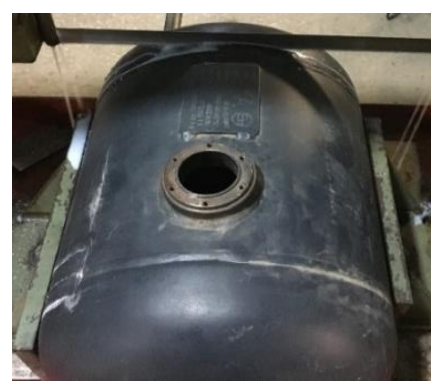

Fig. 21 Cutting operation of ten years used tank

Tensile test is applied to the samples taken from the old tank and the new tank to check whether there was a change in mechanical properties by using Shimadzu AG-X series tensile test machine as shown in Fig. 22.

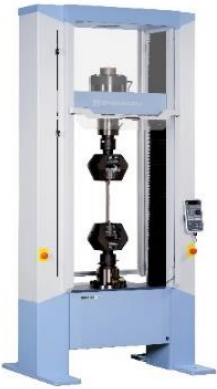

Fig. 22 Shimadzu AG-X series tensile test machine

Especially, the welded areas were subjected to tensile tests and examined for mechanical properties. Yield and ultimate tensile strength values are obtained by using Shimadzu AG-X series tensile test machine for each test specimens.

\section{Results and discussions}

\subsection{Experimental results and discussions}

Improved tank geometry according to the results of FEA technique was presented in the study. In addition, experimental studies were performed to determine used tanks mechanical properties of the used tank and the new tank. It was obtained from the experimental studies that there is no significant change between 10-years tank and the new tank in terms of the mechanical properties as shown in Fig. 23.

When the strength of the specimen taken from the 10 years old tank and new tanks is compared with the unformed plate, it is understood that the yield strength increases as shown in Fig. 23. 
Since there was no coating on the inner surface of the 10 years tank, it has been found to be corroded due to the time and liquid usage inside. Accordingly, it was shown in Fig. 23 that there is a small decrease in yield strength.

It was seen that the ultimate tensile strength increases due to the heat treatment occurring in the welded areas because the welding process is done while forming the tanks. In the same way, it was observed that the ultimate tensile strength decreased due to the corrosion occurring on the inner surface of the 10 years' tank.

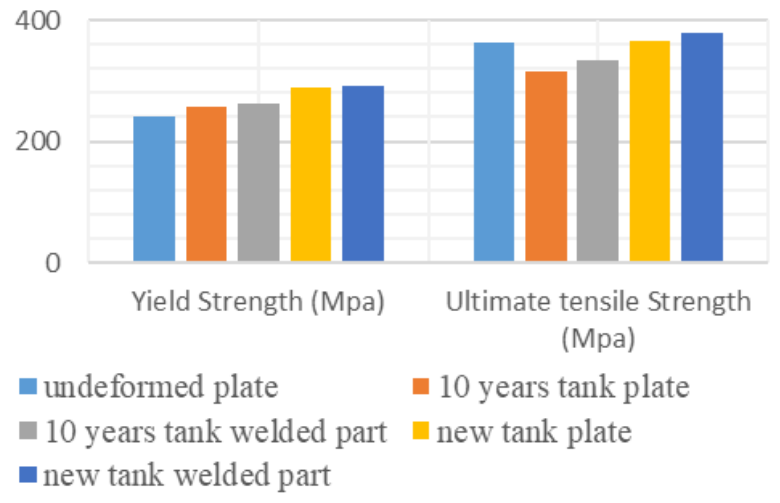

Fig. 23 Experimental results for tested tanks

\subsection{Experimental results and discussions}

The obtained different stress types were given in Table 1 according to the different radius sizes. In addition, fatigue life and safety factor parameters were given in Table 2 according to the FEA results.

Table 1

Lid radius vs stress values for the improved tank

\begin{tabular}{|c|c|c|c|}
\hline $\begin{array}{c}\text { Radius, } \\
\mathrm{mm}\end{array}$ & $\begin{array}{c}\text { Von-Mises, } \\
\mathrm{MPa}\end{array}$ & $\begin{array}{c}\text { Normal X lat- } \\
\text { eral stress, MPa }\end{array}$ & $\begin{array}{c}\text { Normal Y lon- } \\
\text { gitudinal } \\
\text { stress, MPa }\end{array}$ \\
\hline 0 & 255.4 & 267.25 & 203.54 \\
\hline 5 & 245.6 & 250.87 & 203.6 \\
\hline 10 & 235.14 & 238.91 & 201.78 \\
\hline 15 & 232.21 & 230.1 & 203.9 \\
\hline 20 & 233.91 & 219.85 & 204.1 \\
\hline 25 & 236.9 & 214.87 & 203.41 \\
\hline
\end{tabular}

Lid radius vs life and safety factor values

Table 2 for the improved tank

\begin{tabular}{|c|c|c|}
\hline Radius, $\mathrm{mm}$ & Life & Safety factor \\
\hline 0 & 10920 & 1.026 \\
\hline 5 & 12424 & 1.0667 \\
\hline 10 & 14484 & 1.1142 \\
\hline 15 & 15120 & 1.1283 \\
\hline 20 & 14747 & 1.1201 \\
\hline 25 & 14119 & 1.106 \\
\hline
\end{tabular}

When the stress values were investigated in Table 1 , it was determined that $15 \mathrm{~mm}$ radius size has minimum stress value in terms of the von-mises stress, which is design parameter. Furthermore, fatigue life was obtained as maximum, which is nearly 15000 cycle, in $15 \mathrm{~mm}$ radius size for the improved tank as shown in Table 2. Safety factor was also found about 1.13. Obtained results were showed that optimum fillet weld size was achieved on $15 \mathrm{~mm}$ radius.

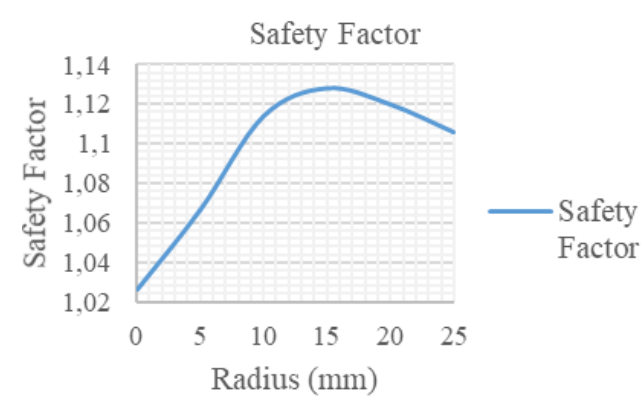

Fig. 24 Change in safety factor at the different radius size for improved tank

Change in safety factor and change in fatigue life was shown in Fig. 24 and Fig. 25. These parameters were obtained as maximum in $15 \mathrm{~mm}$ radius size.

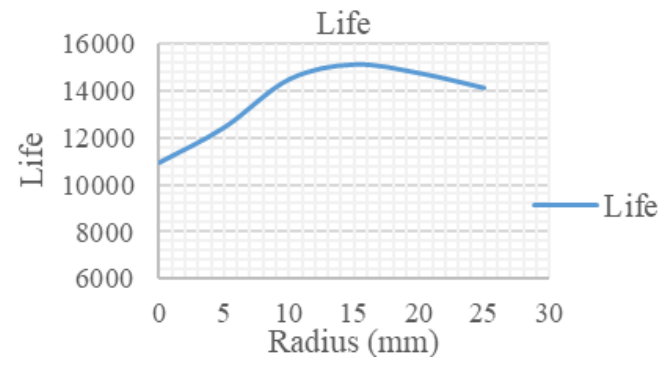

Fig. 25 Change in fatigue life at the different radius size for improved tank

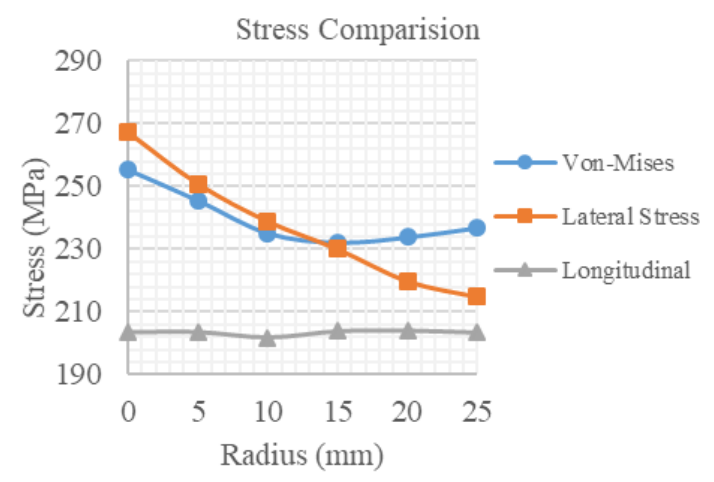

Fig. 26 Stress comparison for the different radius size

When the stress comparison was examined, it was clearly seen that critical stress concept, which is von-mises, is found minimum in $15 \mathrm{~mm}$ radius size. But it was observed that lateral stress has a decrease continuously and longitudinal stress is constant during the analyses as shown in Fig. 26.

\section{Conclusion}

Von-misses stress and deformation parameters were investigated for the Liquefied Petroleum Gas (LPG) storage tanks by using FEA technique. Experimental study was also performed to determine mechanical properties. Tensile test results of 10-years old tank and the new tank were compared. In the experimental study, no significant difference was observed between old tank and the new tank. The 10-year usage period given to such tanks was found to be suitable according to the performed experimental studies. However, in this study, which aims to increase the 10-years usage period, it was shown that this is possible with the improving of the radius of the lid edge. While there is only the 
radius formed by the welding in the tanks produced up to now, it has been determined that the life of the tank was increased by approximately $25 \%$ thanks to this new lid radius. Optimum fillet weld size is determined as novelty.

Radius of the developed tanks were analyzed in different Radius size and the optimum ones were determined according to fatigue life and stress value. Thanks to the improvements made, it was determined that the tanks can be used with a longer life. In addition, since the safety factor is high, safer tanks will be produced and used.

\section{References}

1. Kişioğlu, Y. 2009. Burst tests and volume expansions of vehicle toroidal LPG fuel tanks, Turkish J. Eng. Env. Sci. 33:117-125.

http://dx.doi.org/10.3906/muh-0905-2.

2. Niranjana, S.J.; Patel, S.V.; Dubey, A.K. 2018. Design and analysis of vertical pressure vessel using ASME code and FEA technique, IOP Conf. Series: Materials Science and Engineering 376: 012135. http://dx.doi.org/10.1088/1757-899X/376/1/012135.

3. Žiliukas, A.; Kukis, M. 2013. Pressure vessel with corrugated core numerical strength and experimental analysis, Mechanika 19(4): 374-379.

http://dx.doi.org/10.5755/j01.mech.19.4.3204.

4. Yılmaz, N.F.; Eyercioglu, O. 2008. Near net shape spur gear forging using concave preform, Mechanika 24(2): 268-277. http://dx.doi.org/10.5755/j01.mech.24.2.19334.

5. Sulaimana, S.; Borazjani, S.; Tang, S. H. 2013. Finite element analysis of filament-wound composite pressure vessel under internal pressure, IOP Conf. Series: Materials Science and Engineering 50: 012061. http://dx.doi.org/10.1088/1757-899X/50/1/012061

6. Winarto, W.; Riastuti, R.; Kumeidi, N. 2018. Microstructural and mechanical properties of welded high strength steel plate using SMAW and SAW method for LPG storage tanks, IOP Conf. Series: Materials Science and Engineering 316: 012051. http://dx.doi.org/10.1088/1757-899X/316/1/012051.

7. Liu, D.; Liang, L.; Li, M. 2010. Nonlinear Finite Element Analysis of mechanical characteristics on CFRP composite pressure vessels, IOP Conf. Series: Materials Science and Engineering 10: 012098. http://dx.doi.org/10.1088/1757-899X/10/1/012098.

8. Rashid, Z.A.; Mohd Suhaimi Yeong, A.F.; Alias, A.B.; Ahmad, M.A.; Ali, S.A. 2018. Study of vapour cloud explosion impact from pPressure changes in the liquefied petroleum gas sphere tank storage leakage,IOP Conf. Series: Materials Science and Engineering 358: 012073.

http://dx.doi.org/10.1088/1757-899X/358/1/012073.

9. Aksoley, M.E.; Ozcelik, B.; Bican, I. 2008. Comparison of bursting pressure results of LPG tank using xperimental and finite element method, Journal of Hazardous Materials 151: 699-709.

https://doi.org/10.1016/j.jhazmat.2007.06.051.

10. Tom, A.; Pius, G. M.; Joseph, G.; Jose, J.; Joseph, M.J. 2014. Design and analysis of lpg cylinder, International Journal of Engineering \& Applied Sciences 6(2): 17-31.

http://dx.doi.org/10.24107/ijeas.251225.
11.Stawczyk, J. 2003. Experimental evaluation of LPG tank explosion hazards, Journal of Hazardous Materials B96: 189-200.

https://doi.org/10.1016/S0304-3894(02)00198-X.

12. Razusa, D.; Brinzeaa, V.; Mitua, M.; Oanceab, D. 2009. Explosion characteristics of LPG-air mixtures in closed vessels, Journal of Hazardous Materials 165: 1248-1252. https://doi.org/10.1016/j.jhazmat.2008.10.082.

13. Peprah, G. A.; Morgan, A.; Aidoo, J. 2017. Design of Liquified Petroleum Gas (LPG) pressure vessel for Aboabo No.2 Community, International Journal of Scientific \& Engineering Research 8(4): 1277-1283. Available from Internet: https://www.ijser.org/researchpaper/Design_of_Liquifi ed_Petroleum_Gas_LPG_Pressure_Vessel_for_Aboabo _No2_Community.pdf

\section{H. Doğru, İ. Göv}

\section{EXPERIMENTAL VERIFICATION OF THE LIQUID PETROLEUM GAS (LPG) TANK MATERIAL AND IMPROVEMENT OF THE FATIGUE LIFE ACCORDING TO LID GEOMETRY BY USING FEA TECHNIQUE}

S u m m a r y

Fatigue life of Liquefied Petroleum Gas (LPG) storage tank is investigated in terms of the Von-misses stress and deformation parameters by using finite-element-analysis (FEA) technique. LPG storage tank is used, which has $315 \mathrm{~mm}$ diameter, $460 \mathrm{~mm}$ length and $3 \mathrm{~mm}$ material thickness, in analyses. Experimental studies are performed to validate numerical results. LPG storage tanks, which are used nearly ten-years-old and new tank, is used in experimental study. Material analysis tests are carried out to determine material properties. It is detected that both ten-years-old and new tank are produced from the same material. Tensile test is applied to the samples taken from the ten-years-old and new tank. At the end of the study, it is found that there is no significant change in pressure applied to the body of the tank compared to old and new tank. However, it is seen that this region decreases the life of the tank due to the high density of stress in lid area of the tank. Therefore, analyses are performed using different fillet radii in weld zone. An improvement is performed in radius of the welded area according to analyses results. It is concluded that this improvement could further increase the life of the tank.

Keywords: liquid petroleum gas (LPG) tank, finite element analysis, fatigue life, experimental verification.

Received November 02, 2018 Accepted February 15, 2019 